\title{
Reliability of a smartphone goniometer app compared with traditional goniometer for measuring passive motion at the first metatarsophalangeal joint
}

\author{
Georgie Hales, Richard Keating, Nicola Bear, Katie Warren, Simon Otter
}

From Australasian Podiatry Conference 2015

Queensland, Australia. 6-8 May 2015

\section{Background}

Adequate sagittal plane motion of the first metatarsalphalangeal joint ( $1^{\text {st }}$ MTPJ) is important during normal gait and goniometric measurement is commonly used as a diagnostic and outcome assessment tool for $1^{\text {st }}$ MTPJ pathology. We aimed to determine the intra and interrater reliability of a universal plastic goniometer and a smartphone application when measuring dorsiflexion at the $1^{\text {st }}$ MTPJ.

\section{Method}

A double-blind repeated measures design was used (three raters, one observer) to measure $1^{\text {st }}$ MTPJ dorsiflexion in both feet of 32 healthy volunteers (64 data sets) using a pre-defined measurement protocol. Reliability of the smartphone app (Dr. Goniometer v1.8 installed on an iphone $4 \mathrm{~s}$ ) and a standard universal goniometer was assessed using Interclass correlation coefficients (ICCs) with $95 \%$ confidence intervals.

\section{Results}

Both instruments demonstrated excellent intra-rater reliability (ICC> 0.75), with moderate to good inter-rater reliability:

Universal Goniometer

Inter-rater reliability ICC 0.693 (95\% CI $0.580-0.788)$

Smartphone app

Inter-rater reliability ICC 0.708 (95\% CI 0.597 - 0.799)

\section{Conclusions}

Moderate to high intra and inter-rater reliability of passive $1^{\text {st }}$ MTPJ motion can be achieved with traditional and smartphone-based goniometric measurement. Smartphone applications may provide a slightly higher reliability, but devices should not be used inter-changeably as significant variations in measurement between devices may occur.

Published: 22 September 2015

doi:10.1186/1757-1146-8-S2-P12

Cite this article as: Hales et al:: Reliability of a smartphone goniometer app compared with traditional goniometer for measuring passive motion at the first metatarsophalangeal joint. Journal of Foot and Ankle Research 2015 8(Suppl 2):P12.

* Correspondence: s.otter@brighton.ac.uk

University of Brighton, School of Health Sciences, 49 Darley Road, Eastbourne, BN20 7UR, UK

Submit your next manuscript to BioMed Central and take full advantage of:

- Convenient online submission

- Thorough peer review

- No space constraints or color figure charges

- Immediate publication on acceptance

- Inclusion in PubMed, CAS, Scopus and Google Scholar

- Research which is freely available for redistribution

Submit your manuscript at www.biomedcentral.com/submit
() Biomed Central 